\title{
Anesthetic management of tracheobronchial foreign body removal
}

\section{B. Pradhan}

Department of Anesthesiology, Institute of Medicine, Tribhuvan University Teaching Hospital

Correspondence to: Biswas Pradhan, Department of Anesthesiology, Institute of Medicine, Tribhuvan University Teaching Hospital

Email: biswaspradhan@yahoo.com

\begin{abstract}
Introduction: Tracheobronchial foreign body removal, is a common emergent problem especially in pediatric population and it is associated with greatest challenge to the anesthesiologist as well as to the surgeon as the airway has to be shared by both. Various pulmonary changes associated with foreign body impaction also occurs.

Methods: This is a retrospective analysis of foreign body removal of tracheobronchial tree in Institute of Medicine, Tribhuvan University Teaching Hospital over the last three years (April 2006 - April 2009). Data regarding age, sex, presentation/signs, anesthetic technique, site and types of foreign body, intraoperative events and postoperative outcomes were collected.

Results: The age range of the patients was from 6 months to 18 years. Total cases were 49. Most of the foreign bodies were organic (60\%) and the common site was in right bronchus (64\%).

The cases were managed either with assisted ventilation or controlled ventilation intraoperatively. Most of the cases presented with dyspnoea. Postoperatively few cases (5 cases) needed to be ventilated electively in intensive care unit, while most of the cases needed oxygen supplement for few hours postoperatively.

Conclusions: Anesthetic management of tracheobronchial foreign body is challenging for both the anesthesiologist and the surgeon. The only way for the better outcome, is excellent communication in both parts i.e. anesthesiologists and surgical team, as well as timely information and involvement of other experts like paediatrician, before the procedure.
\end{abstract}

Keywords: Anesthetic management, bronchoscopy, tracheobronchial foreign body

\section{Introduction}

Foreign body removal from tracheobronchial tree creates surmounting challenge, as it needs airway sharing with the endoscopist for the procedure in patients whose lungs are usually compromised for oxygenation, and may also result in chronic lung injury if not managed optimally., ${ }^{1,2}$ Foreign body inhalation is an extremely serious problem in children and sometimes results in fatality. The current mortality rate from foreign body inhalation is between $0 \%$ and $1.8 \%$ according to various studies. ${ }^{3,4}$ In spite of this, undiagnosed and unsuspected foreign bodies still occur in the airway. ${ }^{1}$ To decrease the morbidity and mortality, and optimal outcome of the patient the close cooperation and communication between the anesthesiologists, surgeon, intensivists and the paediatrician for post operative cannot be over emphasized.

\section{Methods}

This is a retrospective analysis of foreign body removal of tracheobronchial tree in Institute of Medicine, Tribhuvan University Teaching Hospital over the last three years (April 2006 - April 2009). Medical records regarding the anesthetic management, surgical records and records of intensive care were collected and analyzed. Analyses were done regarding 
Tracheobronchial foreign body

the patients' age, sex, location of foreign body in airway, symptoms of the patients during presentation, signs, ventilation modes during general anesthesia for removal of foreign body, complications faced and types of foreign bodies extracted. All the patients brought for the foreign body removal in emergency and electively were enrolled in the study. All the patients of both sex groups and ages were enrolled in the study. Informed consent for bronchoscopy and tracheostomy were taken before the procedure. All the cases were done under general anesthesia with spontaneous, assisted or positive pressure ventilation. The foreign bodies were removed with rigid ventilating bronchoscopes. All the patients who were extubated had supplemental oxygen in the post operative period to maintain oxygen saturation more than $95 \%$. All the patients were given dexamethasone before the procedure to minimize oedema formation.

\section{Results}

Total number of patients enrolled in the study were 49, among which 35 (71\%) were male and 14 (29\%) were female. The age group of patients ranged from 9 months to 14 years. Foreign body was found in $43(90 \%)$ cases, whereas in 5 (10\%) cases foreign body was not found. Among the patients whose foreign body was recovered, it was in right bronchi in 25 (51\%), left bronchi in 14 (29\%), trachea in 4 (8\%) and larynx in 1 (2\%) patients. Among signs and symptoms, no patient was symptom free and without any signs. Most of the patients had more than one sign. Shortness of breath was observed in most of the patients (29) followed by rhonchi and fever, stridor, pneumonia and cyanosis.

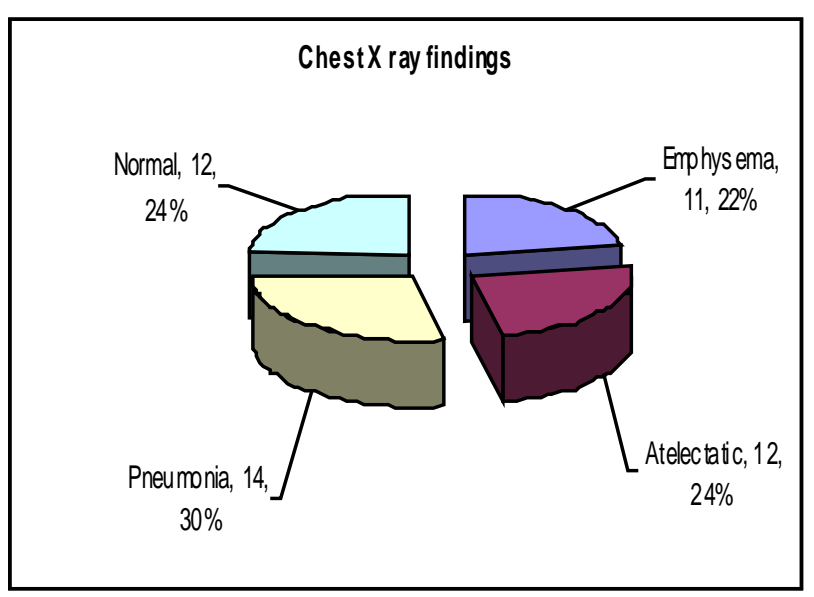

Fig. 1: Chest X-ray findings in patients with foreign body bronchus
Table 1: Variables in patients with foreign body bronchus

\begin{tabular}{|c|c|c|}
\hline \multirow[t]{2}{*}{ Age range } & \multicolumn{2}{|c|}{ 9months to 14 years } \\
\hline & Number & Percentage(\%) \\
\hline Male & 35 & 71 \\
\hline Female & 14 & 29 \\
\hline \multicolumn{3}{|c|}{ Location of Foreign body } \\
\hline Rt. Bronchus & 25 & 51 \\
\hline Lt. Bronchus & 14 & 29 \\
\hline Trachea & 4 & 8 \\
\hline Larynx & 1 & 2 \\
\hline Not found & 5 & 10 \\
\hline \multicolumn{3}{|l|}{ Signs/Symptoms } \\
\hline SOB & 29 & \\
\hline Stridor & 15 & \\
\hline Rhonchi/Fever & 19 & \\
\hline Pneumonia & 14 & \\
\hline Cyanosis & 6 & \\
\hline \multicolumn{3}{|l|}{ Ventilation } \\
\hline Spontaneous & 0 & \\
\hline Assisted & 28 & 57 \\
\hline Controlled & 21 & 43 \\
\hline \multicolumn{3}{|l|}{ Complications } \\
\hline Нурохіа & 35 & 48 \\
\hline Bradycardia & 29 & 39 \\
\hline Cardiac arrest & 4 & 5 \\
\hline Post op ventilation & 4 & 5 \\
\hline Deceased & 2 & 3 \\
\hline
\end{tabular}

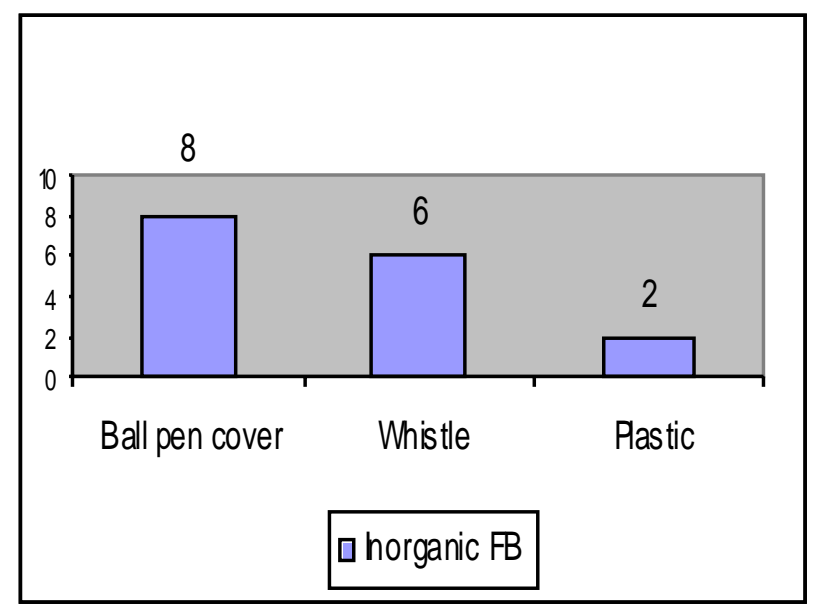

Fig 2: Type of organic and inorganic foreign bodies recovered 


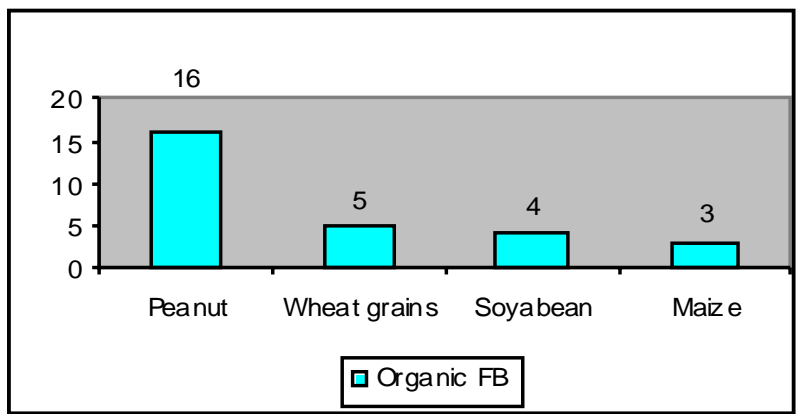

Fig. 3: Type of foreign body recovered

Foreign body removal was done under general anesthesia in all the cases. Ventilation mode was assisted in 28(57\%) cases and $21(43 \%)$ patients were managed with controlled ventilation after administration of paralyzing agent. Among the complications, 35(48\%) patients developed hypoxia (oxygen saturation < 90\%), 29 (39\%) had bradycardia, 4 (5\%) had cardiac arrest, 4(5\%) needed mechanical ventilation in the post operative period. There was mortality of 2(3\%) patients. Some of the patients were observed to have more than one complication. The patients who had fatality were in mechanical ventilation for less than 24 hours. Among the foreign bodies retrieved, 28(64\%) and 16(36\%) were organic and inorganic foreign bodies respectively (Fig. 2, 3).

\section{Discussion}

The incidence of tracheo bronchial foreign bodies is higher in children in all the studies than adults. Children of ages 13 years are more vulnerable, and predilection is towards the male child in series of studies. ${ }^{1,2,5,6-8}$ The incidence could be higher in children due to their curiosity to explore things by keeping things in mouth. The preponderance towards male children is regarded to be high due to their high activity than the female children. Not only that the absence of molar teeth might make the accidental migration of food particle in the airway during chewing and swallowing in haste. ${ }^{1,7,8}$

In children, the risk is more: mainly due to physiological reduced respiratory reserve, early airway closure, increased oxygen consumption and especially increased shunting due to lung pathology that follows the obstruction of part of the lung due to tracheobronchial foreign bodies. The effect in the lung depends mainly on duration, site and degree of obstruction and also the types of foreign body, whether organic or inorganic. ${ }^{1-3,9-11}$ The lungs may be emphysematous if the foreign body causes check valve effect causing obstruction mainly during expiration, collapse of the lung in ball valve effect that causes obstruction during inspiration. It may cause partial obstruction as in bypass valve without any significant radiological changes and total obstruction, as in stop valve mechanism, gives the feature of collapse. ${ }^{1}$ Almost all the authors showed the prevalence of children in their studies. 1-3 years of male children are more common to have foreign bodies..$^{2,12,13}$ This study also has similar finding.

Preoperative assessment of the patient is very important, as it decides the urgency of the management and outcome of the patients. It should be focused on the cyanosis of the patient, severity of airway obstruction (use of accessory muscles of respiration, stridor, and wheeze). Loss of consciousness in central nervous system assessment is an alarming sign, as it can be precipitated by hypoxia. Depending on the type of obstruction the chest x-ray may reveal emphysematous lung, collapse of segment or whole hemithorax, no changes, pneumonic consolidation or even mediastinal shift due to hyperinflation of the lung. ${ }^{10,14,15}$ Some studies have found the emphysematous changes more, others found the atelectatic changes more. ${ }^{2,5-7} 33-55 \%$ patients had normal finding in the study carried out by Rovin, et al. ${ }^{7}$ In this study the most common presentation was pneumonia (30\%).

Healy GB and Young, et al. in their study have found that the foreign bodies in trachea and larynx are associated with increased morbidity and mortality, as they are more mobile and there is always a chance of sudden total occlusion. ${ }^{9,14}$ Heimlich manouvre, both in adults and children could be life saving procedure and should be performed without delay in patients with severe respiratory distress. Consent for tracheostomy should be taken beforehand for emergency airway management. Sedatives are usually contraindicated, even if the patient seems agitated which is commonly due to hypoxia and discomfort. Anticholinergic like atropine preferably should be used to decrease secretions. Its sympathomimetic property is also beneficial, especially in the children, for the prevention of hypoxia induced bradycardia and vagal stimulation during intubation and during bronchoscopy. ${ }^{2,3,8,9,13}$ Fasting protocol should be balanced against grade of airway compromise, and prioritized accordingly. In case of full stomach, the stomach should be emptied by inserting nasogastric tube and aspiration after airway is secure. 8,10

General anesthesia is the choice of anesthetic technique in all the cases. The choice of inducing agents could be ketamine, propofol, thiopentone or even inhalational agents. Ketamine is preferred in the patients with bronchoconstriction and are planned to maintain in spontaneous mode of ventilation. It has added benefit of maintainance of airway tone as well. The choice of inhalational agent is sevoflurane in case of children due to 
Tracheobronchial foreign body

its fast onset of action and the patient can be maintained in spontaneous mode of ventilation with the same inhalational agent. Propofol and thiopentone has the disadvantages of decreasing motor tone of airway and apnoea with its inducing dose. The patients maintaining with spontaneous respiration may experience total obstruction of ventilation after inducing with these agents. ${ }^{2,8,10}$ Intubation of the airway may be done with or without muscle relaxant. If the mode of ventilation planned is spontaneous, intubation is done after deepening with inhalational agent, and topical lignocaine spray may be used to blunt the stress of laryngoscopy. The lignocaine spray also decreases the depth of anesthesia during intubation in spontaneous mode. If controlled ventilation is planned, then the intubation is performed after giving short acting muscle relaxant like succinylcholine.,2,810 Ronald et al have found that there is no significant difference in outcome of the patients irrespective of the modes of ventilation, either spontaneous/assisted or controlled ventilation. ${ }^{10}$ However, the risks and benefits of using muscle relaxant should be weighed logically and invidualised according to the patients' condition.

Spontaneous ventilation has the advantages like less chance of pushing foreign body more distally, avoidance of sudden "Ball valve" mechanism and total airway obstruction and the ventilation is also maintained during foreign body retrieval. However the depth of anesthesia required in spontaneous ventilation is higher. ${ }^{1,11,16}$ With controlled ventilation, the anesthetic depth required is less, the atelectatic parts of the lungs are opened and it also facilitates foreign body retrieval as there is no mobility in airway. Pushing of airway more distally and development of "Ball valve mechanism" during ventilation are its major side effects. ${ }^{4,11,17}$

Ventilation techniques during bronchoscope include ventilating bronchoscope with side port for ventilation, high frequency jet ventilation, apnoeic oxygenation or even use of extra corporeal membrane oxygenation. The most popular technique is rigid ventilating bronchoscope..$^{2,5,8,10}$ Apnoeic oxygenation should not be more than 5 mins. ${ }^{16}$ Most of the reports are with the rigid ventilating bronchoscopes, whereas A. Debeljak, et al. have compared the foreign body removal with flexible bronchoscope versus rigid bronchoscope. In their study they have found that the results are better with flexible bronchoscopes. ${ }^{12}$

Postoperative management should be very meticulous and depends upon the condition of the patient and the complications encountered like subglottic edema, bronchospasm, collapsed lung segment, pneumonia, pneumothorax, etc. The role of paediatrician, intensivist for the post operative management of the paediatric patient is invaluable, and should be sought prior to the procedure.

\section{Conclusions}

Foreign body removal of tracheobronchial tree is a great challenge for the anesthesiologists, as it demands optimum communication and airway sharing with the endoscopist. The anesthetic management may be individualized according to the patients' presentation and condition. The multidisciplinary approach involving also the paediatrician and intesivists is mandatory, for the benefit of the patients.

\section{References}

1. Chatterji S, Chatterji P. The management of foreign bodies in the air passages. Anaesthesia. 1972; 27:390-5.

2. KalyanappagolVT, Kulkarni NH, Bidri LH. Management of tracheobronchial foreign body aspirations in paediatric age group - a 10 year retrospective analysis. Ind J Anaesth. 2007;51(1):20-3.

3. Young LW, Seibert RW, Seibert JJ. Radiological case of the month. Am J Dis Child 1979;133:749.

4. Kim IG, BrummittWM, Humphry A, et al. Foreign body in the airway: a review of 202 cases. Laryngoscopy. 1973;83:347.

5. Baraka A. Bronchoscopic removal of inhaled foreign bodies in children. Br J Anaesth. 1974;46:124.

6. Stark DC, Biller HF. Aspiration of foreign bodies: diagnosis and management. Intl Anesthesiol Clin. 1977;15:117-45.

7. Shivakumar AM, Naik AS, Prashanth KB, et al. Tracheobronchial foreign bodies. Indian J. Pediatr. 2003 Oct;70(10):793-7.

8. . Litman RS, Ponnuri, J, Trogan I. Anesthesia for tracheal or bronchial foreign body removal in children: an analysis of ninety four cases. Anesth Analg. 2000;91:1389-91.

9. Cataneo AJ, Reibscheid SM, Ruiz Junior RL, et al. Foreign body in the tracheobronchial tree. Clin Pediatr (Phila). 1997 Dec;36(12):701-6.

10. HKK Tan, SS Tan. Inhaled foreign bodies in children anesthetic consideration. Singapore Med. J. 2000;4:506-10.

11. Brown TC, Clark CM. Inhaled foreign bodies in children. Med J Aust. 1983;2:322-6.

12. Cohen SR, Herbert WI, et al. Foreign bodies in the 
airway: five year retrospective study with special reference to management. Ann Otol Rhinol Laryngol. 1980;89:437-42.

13. Healy GB. Foreign bodies of the air and food passages in children. Am J Dis Child. 1987;141(3):249.

14. Rovin JD, Roger MB. Pediatric foreign body aspiration. Pediatric Review. 2000; 21:86-90.

15. Agarwal RK, Banerjee G, Shembish N, Jamal BA, Kareemullah C, Swaleh A. Foreign bodies in the tracheobronchial tree. A review of 102 cases, Benghazi, Libya. Ann Trop Paediatr. 1988 Dec;8(4):213-6.

16. Debeljak A, Sorli J, Music E, Kecelj P. Bronchoscopic removal of foreign bodies in adults: experience with 62 patients from 1974-1998. Eur Respir J. 1999;14: 792-5.

17. Morse HR, Hartmann MM. General anesthesia for per oral endoscopy: apnoeic technique. Ann Otol Rhinol Laryngol. 1966;75:1040-8. 